Eva Álvarez Ramos (ed.)

Humanidades digitales:

una mirada desde la interdisciplinariedad

La imupción de lo digital en el mundo de las humanidades ha puesto en evidencia la necesidad de un replanteamiento bastante radical de nuestra relación con el objeto de estudio. Una variación que afecta a la totalidad del proceso que va de la creación a la recepción: escritura, transmisión, anátisis, lectura, preservacion y apticaciôn a t. ensenanza.

De todos estos aspectos se ocupan las paginas del presente volumen atentas a los cambios que to digital ha venido a imponer sobre la cateqoria de "autor literario" sobre la escritura misma; al lector, tan distinto del tradicional, que emerge de los transmedia; a la difusion masiva de la literatura; a las novedades denvadas de la

ncorporacion al proceso de anolisis de metodos citantitatives o las que amanan de th edición digital y finalmente, a la renovaciôn didáctica que impone la adecuación del aula a to tecnológico.

\section{La editora}

Eva Álvarez Ramos es doctora en Fitologia Hispanica y Licenciada en filología Hispánica, en Filología Germánica: Alemán y en Teoría de La Literatura y Literatura Comparada. Actualmente es profesora en la Universidad de Valladolid. Sus líneas de investiga ciôn giran en torno a la literatura infantil, la didactica de la lenqua y la liferatura y la poesía espanola contemporanea. Es autora de diversas publicaciones sobre el uso y l. implementación de los medios digitales en la enseñanza de la lengua y la literatura.
Eva Álvarez Ramos (ed.)

Humanidades digitales: una mirada desde la interdisciplinariedad

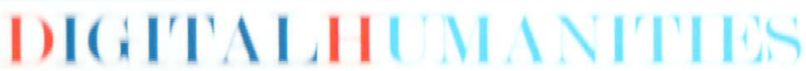

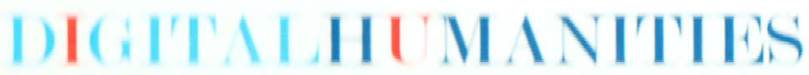

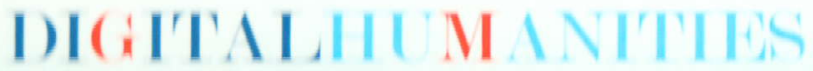 \\ I)I(iIT:MIIIUMANITIES

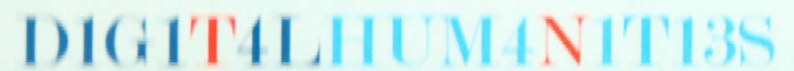 \\ D) IGITTIMUMANITIES

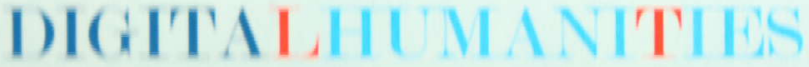 \\ DIGITII HOMANITIES \\ DIGITALIII I VITIES \\ I) IGIITIIIIUMANITIES




\title{
Humanidades digitales: una mirada desde la interdisciplinariedad
}

\author{
量 \\ PETER LANG
}


Bibliografische Information der Deutschen Nationalbibliothek

Die Deutsche Nationalbibliothek verzeichnet diese Publikation

in der Deutschen Nationalbibliografie; detaillierte bibliografische

Daten sind im Internet über http://dnb.d-nb.de abrufbar.

Imagen de la sobrecubierta: Eva Álvarez Ramos

La edición de este libro se ha realizado en el marco de la Unidad de Investigación Consolidada, con sello ANEP, "Literatura Española y Humanidades

Digitales" (Código UIC2016-205), de la Junta de Castilla y León.

Todos los trabajos incluidos en el presente volumen han sido sometidos a una revisión por pares a doble ciego.

Druck und Bindung: CPI books GmbH, Leck

$$
\begin{gathered}
\text { ISBN 978-3-631-78977-3 (Print) } \\
\text { E-ISBN 978-3-631-79376-3 (E-PDF) } \\
\text { E-ISBN 978-3-631-79377-0 (EPUB) } \\
\text { E-ISBN 978-3-631-79378-7 (MOBI) } \\
\text { DOI 10.3726/b15801 }
\end{gathered}
$$

(C) Peter Lang GmbH

Internationaler Verlag der Wissenschaften

$$
\text { Berlin } 2019
$$

Alle Rechte vorbehalten

Peter Lang - Berlin • Bern • Bruxelles • New York •

$$
\text { Oxford - Warszawa } \cdot \text { Wien }
$$

Das Werk einschließlich aller seiner Teile ist urheberrechtlich geschützt. Jede Verwertung außerhalb der engen Grenzen des Urheberrechtsgesetzes ist ohne Zustimmung des Verlages unzulässig und strafbar. Das gilt insbesondere für

Vervielfältigungen, Übersetzungen, Mikroverfilmungen und die Einspeicherung und Verarbeitung in elektronischen Systemen.

Diese Publikation wurde begutachtet.

\section{Índice}

Palabras preliminares:

A vueltas con las humanidades digitales y su ámbito de aplicación .........7

I. Humanidades digitales desde una perspectiva global

Javier Blasco (Universidad de Valladolid)

El vértigo de las humanidades ante lo digital:

hacia un nuevo paradigma

Rocio Badia Fumaz (Universidad Complutense de Madrid)

Viejos y nuevos retos para la categoría de autor literario.

Una mirada desde las humanidades digitales....

II. La gestión y el análisis de datos y las humanidades digitales

Encarna Alonso Valero (Universidad de Granada)

Poesía, redes y vigilancia tecnológica.....

Zoraida Sánchez Mateo (Universidad de Valladolid)

Análisis cuantitativos aplicados a la lírica:

La poesía indubitada profana de Damián Cornejo y

de León Marchante

III. Nuevas disciplinas humanísticas a la sombra de lo digital

Pedro Dono López Idalete Maria Silva Dias y

Sílvia Lima Gonçalves Araújo, (Universidade do Minbo)

Para una edición digital de documentación notarial

gallega del siglo XIII.

María Martinez Deyros (Universidad Complutense de Madrid) Antetexto electrónico: la digitalización del proceso de escritura .105

www.peterlang.com 
IV. Presencia de las humanidades digitales en la educación

Manuel Francisco Romero Oliva y

Hugo Heredia Ponce (Universidad de Cádiz)

Prácticas lectoras en formato digital:

apostando por las humanidades en Educación

María Esther Pérez Dalmeda (Spanish World Hong Kong)

El cíborg como metáfora intertextual:

un experimento narratológico para la inclusión en el aula

V. Creación y recepción literaria al amparo de las humanidades digitales

Eva Álvarez Ramos (Universidad de Valladolid)

Lecturas multimediales y performativas:

producción y consumo de la poesía juvenil española en

la era digita

Daniel Escandell Montiel (Manchester Metropolitan University)

Poesía en realidad virtual:

poshumanismo y mundos simulados en la creación artística 